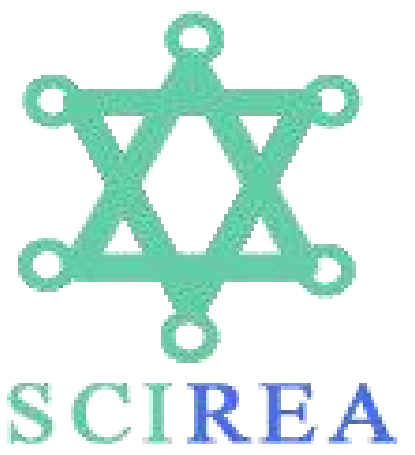

SCIREA Journal of Clinical Medicine

ISSN: 2706-8870

http://www.scirea.org/journal/CM

September 28, 2021

Volume 6, Issue 5, October 2021

\title{
PHYSCIAN POWER
}

\section{García-Solís Eduardo*}

* Physician

Secretary of Health of de State Campeche, Mexico

Bioethics Commission

Correspondence : Calle 49B x 14, Altos del Hospital "Dr. Manuel Campos ", Barrio de Guadalupe, CP 24010, San Francisco de Campeche, Campeche.

Email: eduardogarsol@gmail.com

\begin{abstract}
The physician since the time of Hippocrates, more than 2000 years ago, has been considered to have a power. The power of healing. However, over the years, that power has sometimes been degraded. Obsolete hierarchies have been created and perpetuated in hospitals, giving rise to power in medicine. Which has led to the abuse not only of patients, but also of medical students and other health professionals. This adds to the lack of supervision of health and educational authorities. In Mexico, medical admission systems are oriented to test scores, which means that a physician with good grades is excellent for studying medicine. However, that doesn't necessarily translate into what patients often consider important: a physician who listens to them, cares, has empathy, and treats them like a human asking for help. Research has shown that emotional intelligence can be helpful (EQ). Some medical schools are working to change their admission
\end{abstract}


criteria to better reflect this need. We do not need more powerful physician in medicine, what we need are good physicians.

Keywords: Physician, power, medicine

\section{TEXT}

Since the time of Hippocrates, more than 2000 years ago, the physician has been considered to have a power. The power of healing. However, over the years, that power has sometimes been degraded. In January 2016, a renowned physician sexually assaulted a black patient ${ }^{1}$, at one of the most prestigious academic hospitals in the United States of America, It happened right in the emergency room, a place he went to hoping for care, and initially no one believed him. When the semen analysis showed that she was in fact right, that this doctor had drugged her and proceeded to ejaculate on her, many questioned how it could have been possible. For most health personnel, this would seem surprising and not credible. Probably his power, prestige, and sense of invincible were all factors that really made him feel like he could get away with it. How many similar cases are known? Physician who are considered non plus ultra, cases of sexual, physical and psychological abuse are reported ${ }^{2}$ and most of the time nothing happens. Obsolete hierarchies have been created and perpetuated in hospitals, giving rise to power in medicine.

Which has led to the abuse not only of patients, but also of medical students and other health professionals. Teaching medicine, in medical residencies, there are physicians who are considered to have the power to influence their subordinates, not only academically, sometimes in their private lives. Coupled with the lack of supervision by health and educational authorities. If physicians have the potential to become abusive, why do they do it and how can we stop it? Some have pointed to the growing burnout epidemic and among physicians-in-training as contributors. In a study ${ }^{3}$ The researchers found that medical students who were more "exhausted" were more likely to behave unprofessionally and less humanely in caring for patients, especially the vulnerable. Moreover, it is mainly in that population that the patient believes that the doctor has an apostolic power, that everything he said would be accepted and believed as true. The doctor's responsibility is to his patients. Study medicine to help. Some consider that they have a 
power, sometimes between deciding life or death, as is the case with euthanasia. Without forgetting the economic power, where doctors make a profit out of the profession.

Another reason may be that we are not selecting the right kind of people to be physician. In medical admission, systems are oriented to test scores, which means that an applicant with good grades is excellent for studying medicine. However, that doesn't necessarily translate into what patients often consider important: a physician who listens to them, cares, has empathy, and treats them like human beings asking for help. Research has shown that emotional intelligence is helpful (EQ). In contrast, with emotional intelligence (IQ). Some medical schools are changing to modify their admission criteria to better reflect this need, but most are not. However, aside from these reasons, we must not underestimate the fact that power inherently corrupts, especially when there is no system to keep it in check. Their institutions have protected many of the prestigious doctors who got away with harming others.

At Yale School of Medicine ${ }^{4}$, a physician remained director of his research institute and was invited to return as head of his division after sexually harassing students. The reality is that big name physician are important to big name institutions. Some provide large amounts of research grants; others increase the influence and prestige of the place where they work. But those in charge who have the power to do something about abuse need to ask themselves: ¿Is a patient's safety worth more than saving face or protecting research money? Power permeates society sometimes makes the doctor feel powerful. The doctor should be empathetic, privileging the most vulnerable, giving the best of himself in knowledge and skills.

Patients deserve the best physician, but the best physician are not always the most famous. When it comes to helping, the patient will not care how many titles are behind the name of their doctors, how many publications, awards. When the disease occurs, you will want someone who is by your side, holding your hand, treating you with respect and care. Recognizing that he is a human being. Physician who think they are God will not be able to do this.

\section{CONCLUSION}

No more powerful physicians are need in medicine, what is needed are good physicians. 


\section{References}

[1] One Night at Mount Sinai, Aja Newman went to the emergency room for shoulder pain. Her doctor was a superstar. What is the worst that could happen? The Cut oct 15201

[2] Harassment and discrimination in medical training: A systematic review and meta-analysis. Fnais N, Soobiah C, Chen MH, Lillie E Acade Med F, 2014 mayo; 89 (5): 817-27

[3] Changes in Empathy during Medical Education: An Example from Turkey Artiran Igde Pak J med Sci 017 Sept-Oct; 33(5):1177-1181

[4] Yale Medical School Removs Doctor after Sexual Harassment Finding, The New York Times, 14 November 2014 